\title{
Fixed Point Theorem in $\varepsilon$-chainable Fuzzy Metric Spaces using Implicit Relations
}

\author{
Bijendra Singh \\ School of studies in Mathematics \\ Vikram University \\ Ujjain, M.P. (INDIA)
}

\begin{abstract}
The purpose of this paper is to present a common fixed point theorem for weakly compatible four self maps using implicit relation on a complete fuzzy metric space. Our results also extended the result of R. Rana, R. C. Dimri et. al. [13]
\end{abstract}

\section{AMS SUBJECT CLASSIFICATION: 47H10, 54H25}

\section{Keywords}

Fuzzy metric space, $\varepsilon$-chainable fuzzy metric space, compatible mapping, weakly compatible mapping, implicit relation and common fixed point.

\section{INTRODUCTION}

Fixed point theorems in fuzzy metric spaces satisfying some contractive condition is a central area of research now a days. Zadeh [17] initiated the concept of fuzzy sets in 1965. Many authors used this concept in the growth of Fuzzy Mathematics Kramosil and Michalek [8] introduced the concept of fuzzy metric space. Geroge and Veeramani [3] modified this concept of fuzzy metric space but Grabiec [5] obtained the fuzzy version of Banach contradiction principle. Sessa introduced the notion of weak commuting property. Further, Jungck introduced more generalized condition explained as compatibility in metric space. Recently in 2006, Jungck and Rhoades [7] introduced the concept of weakly compatible maps. The notions of compatible mapping in fuzzy metric space have been introduced by Cho [2]

In 1994, S.N. Mishra et. al. [10] introduced the notion of Compatible maps in FM space. B.Singh and Jain [14] studied the notions of semi compatibility and weak compatibility of maps in fuzzy metric spaces. B. Singh and Chauhan [15] started the concept of compatibility in fuzzy metric space: Popa [11] prove of some result of fixed point theorems for weakly compatible non continuous mapping using implicit relation. Imdad [06] extended the work of popa. Singh and Jain [14] analysis and gave new extended result in fuzzy metric spaces.

In this paper our objectives is to prove a common fixed theorem for weakly compatible maps on a complete $\varepsilon$-. chainable fuzzy metric space satisfying an implicit relation. The property of $\varepsilon$-.chainable fuzzy metric are characterized to obtain fixed point. Our result generalized, extend several comparable results in existing literature.

\author{
Mahendra S. Bhadauriya \\ Vikrant Institute of Technology \& Management \\ Gwalior, M.P. (INDIA)
}

\section{PREMINILARIES}

Definition 2.1 [17] :- A fuzzy set $A$ in $X$ is a function with domain $\mathrm{X}$ and values in[0,1].

Definition $2.2[1]:-$ A binary operation $*:[0,1]^{4} \rightarrow[0,1]$ is called a continuous t-norm if $([0,1], *)$ is an Abelian monoid with the unity 1 such that

$$
\mathrm{a} * \mathrm{~b} \leq \mathrm{c} * \mathrm{~d}
$$

Whenever $a \leq c$ and $\mathrm{b} \leq \mathrm{d}$ for all $\mathrm{a}, \mathrm{b}, \mathrm{c}, \mathrm{d} \in[0,1]$

Example of t-norm :

$$
\begin{array}{ll} 
& a * b=a b \\
\text { and } & a * b=\min \{a, b\}
\end{array}
$$

Definition 2.3 [2] :- The 3-tuple (X, M,*) is called a fuzzy metric space if $X$ is an arbitrary set, $*$ is a continuous t-norm and $\mathrm{M}$ is a fuzzy set in $\left(X^{2} \times(0, \infty)\right)$ satisfying the following condition for all $\mathrm{x}, \mathrm{y}, \mathrm{z} \in \mathrm{X}$ and $\mathrm{s}, \mathrm{t}$. $>\mathrm{o}$

$$
\begin{array}{ll}
(\mathrm{FM}-1) & \mathrm{M}(\mathrm{x}, \mathrm{y}, \mathrm{o})=0 \\
(\mathrm{FM}-2) & \mathrm{M}(\mathrm{x}, \mathrm{y}, \mathrm{t})=1 \text { for all } \mathrm{t}>\mathrm{o} \text { iff } \mathrm{x}=\mathrm{y} \\
(\mathrm{FM}-3) & \mathrm{M}(\mathrm{x}, \mathrm{y}, \mathrm{t})=\mathrm{M}(\mathrm{y}, \mathrm{x}, \mathrm{t}) \\
(\mathrm{FM}-4) & \mathrm{M}(\mathrm{x}, \mathrm{y}, \mathrm{t}) * \mathrm{M}(\mathrm{y}, \mathrm{z}, \mathrm{t}) \leq \mathrm{M}(\mathrm{x}, \mathrm{z}, \mathrm{t}+\mathrm{s}) \\
(\text { FM-5) } & \mathrm{M}(\mathrm{x}, \mathrm{y}, .):[0, \infty) \rightarrow[0,1] \text { is lefts }
\end{array}
$$
continuous .

Note that $\mathrm{M}(\mathrm{x}, \mathrm{y}, \mathrm{t})$ can be thought of as the degree of nearness between $\mathrm{x}$ and $\mathrm{y}$ with respect to $\mathrm{t}$.

Example 2.1 [16] :- Every metric spaces induces a fuzzy metric spaces.

Let $(\mathrm{X}, \mathrm{d})$ be a metric spaces. define $\mathrm{a} * \mathrm{~b}=\mathrm{a} \mathrm{b}$ and $M(x, y, t)=\frac{k t^{n}}{k t^{n}+m d(x, y)} \quad \mathrm{k}, \mathrm{m}, \mathrm{n} \in R^{+}$

Then $\left(X, M^{*}\right)$ is a fuzzy metric spaces. If we put $k=m=n=1$

we get $\quad M(x, y, t)=\frac{t}{t+d(x, y)}$

The fuzzy metric induced by a metric $d$ is referred to as a standard fuzzy metric. 
Definition 2.4 [5] :- A Sequence $\left\{\mathrm{x}_{\mathrm{n}}\right\}$ in a fuzzy metric $\operatorname{space}(X, M, *)$ is said to be convergent to a point $\mathrm{x} \in \mathrm{X}$ such that -

$$
\operatorname{Lim}_{n \rightarrow \infty} x_{n}=x,
$$

if for each $\varepsilon>0$ and for each $\mathrm{t}>0$, there exist $\mathrm{n}_{0} \in \mathrm{N}$, s.t. $\mathrm{M}\left(\mathrm{x}_{\mathrm{n}}, \mathrm{x}, \mathrm{t}\right)>1-\varepsilon$

for all $\mathrm{n} \geq \mathrm{n}_{0}$

Lemma 2.1 [3] :- A Sequence $\left\{x_{n}\right\}$ in a fuzzy metric space $\left(\mathrm{X}, \mathrm{M},{ }^{*}\right)$ converges to a point $\mathrm{x} \in \mathrm{X}$ if and only if

$\mathrm{M}\left(\mathrm{x}_{\mathrm{n}}, \mathrm{x}, \mathrm{t}\right)=1$, for all $\mathrm{t}>0$

Definition 2.5 [4] :- A sequence $\left\{x_{n}\right\}$ in a FM space (X, M, *) is defined as Cauchy Sequence if for each $\varepsilon>0$ and $\mathrm{t}>0$, there exists $\mathrm{n}_{0} \in \mathrm{N}$, s.t. $\mathrm{M}\left(\mathrm{x}_{\mathrm{n}}, \mathrm{x}_{\mathrm{m}}, \mathrm{t}\right)>1-\varepsilon$ for all $\mathrm{n}, \mathrm{m}>\mathrm{n}_{0}$. A fuzzy metric space in which every Cauchy sequence is convergent is said to be complete.

Example 2.2 [9] :- Let $\mathrm{X}=\left\{\frac{1}{n}: n=1,2,3, \ldots \ldots \ldots \ldots \ldots . . . . ..\right\} \cup\{0\}$ and $*$ be the continuous t-norm defined by $\mathrm{a} * \mathrm{~b}=\mathrm{a} \mathrm{b}$ for all $\mathrm{a}, \mathrm{b} \in[0,1]$.for each $\mathrm{t} \in(0, \infty)$ and $\mathrm{x}, \mathrm{y} \in \mathrm{X}$

Define $M(x, y, t)=\frac{t}{t+d(x, y)}$ if $\mathrm{t}>0$

And $M(x, y, t)=0$ if $t=0$

Then clearly $\left(\mathrm{X}, \mathrm{M},{ }^{*}\right)$ is complete fuzzy metric spaces.

Definition 2.6 [15] :- Self mapping A and $S$ of a fuzzy metric space $(\mathrm{X}, \mathrm{M}, *)$ are said to be compatible

if $\mathrm{M}\left(\mathrm{ASx}_{\mathrm{n}}, \mathrm{SAx}_{\mathrm{n}}, \mathrm{t}\right) \rightarrow 1$ for all $\mathrm{t}>0$, Whenever $\left\{\mathrm{x}_{\mathrm{n}}\right\}$ is a sequence in $\mathrm{X}$ such-that $\mathrm{Sx}_{\mathrm{n}}, \mathrm{Ax}_{\mathrm{n}}, \rightarrow \mathrm{p}$ for some $\mathrm{p}$ in $\mathrm{X}$ as $n \rightarrow \infty$.

Definition: 2.7 [7] :- Two self maps $\mathrm{S}$ and $\mathrm{T}$ of fuzzy metric space $(\mathrm{X}, \mathrm{M}, *)$ are said to be Weakly Compatible if they commute at their coincidence point i.e.

$\mathrm{STu}=\mathrm{TSu}$ whenever $\mathrm{Su}=\mathrm{Tu}, \mathrm{u} \in \mathrm{X}$

The concept of weak compatibility is most general among all the commutative. Concept, Each pair of Compatible self maps is weakly compatible but the converse is not true.

Definition 2.8 [13] :- Let $(X, M, *)$ is called a fuzzy metric space and $\varepsilon>0$, A finite sequence $\mathrm{x}=\mathrm{x}_{0}, \mathrm{x}_{1}, \mathrm{x}_{2}, \ldots \ldots \mathrm{x}_{\mathrm{n}}=\mathrm{y}$ is called to be $\varepsilon$ - Chain from $\mathrm{x}$ to $\mathrm{y}$

If $\mathrm{M}\left(\mathrm{x}_{\mathrm{i}}, \mathrm{x}_{\mathrm{i}-1}, \mathrm{t}\right)>1-\varepsilon$ for all $\mathrm{t}>0$ and $\mathrm{i}=1,2,3$, , n

A fuzzy metric space $(\mathrm{X}, \mathrm{M}, *)$ is called as $\varepsilon$ - chainable if for any $\mathrm{x}, \mathrm{y} \in \mathrm{X}$, there exists a $\varepsilon$-chain from $\mathrm{x}$ to $\mathrm{y}$.

Lemma 2.2 [5] :- Let (X, M, *) be a fuzzy metric space, then for all $\mathrm{x}, \mathrm{y} \in \mathrm{X}, \mathrm{M}(\mathrm{x}, \mathrm{y}, \mathrm{.})$ is non decreasing.

Lemma 2.3 [13] :- Let (X, M, *) be a fuzzy metric space, if there exist $\mathrm{k} \in(0,1)$ such that $\mathrm{M}(\mathrm{x}, \mathrm{y}, \mathrm{kt}) \geq \mathrm{M}(\mathrm{x}, \mathrm{y}, \mathrm{t})$ for all $\mathrm{x}, \mathrm{y} \in \mathrm{x}$ and $\mathrm{t}>0$, then $\mathrm{x}=\mathrm{y}$.

Lemma 2.4 [12]:- Let $(X, M, *)$ be a fuzzy metric space, then $\mathrm{M}$ is a continuous function on $\mathrm{X}^{2} \times(0, \infty)$
A Class of Implicit Relation :- Let $\Phi$ be the set of all real and continuous of $\phi:[0,1]^{4} \rightarrow R$ satisfying the following conditions.

(1) $\phi$ is non increasing in second, third and fourth argument.

(2) $\phi(\mathrm{u}, \mathrm{v}, \mathrm{v}, \mathrm{u}) \geq 0$ or $\phi(\mathrm{u}, \mathrm{v}, \mathrm{v}, \mathrm{v}) \geq 0$ or

$\phi(\mathrm{u}, \mathrm{v}, \mathrm{v}, 1) \geq 0$

Implies that $\mathrm{u} \geq \mathrm{v}$ for all $\mathrm{u}, \mathrm{v} \in[0,1]$

Example :- $\phi\left(\mathrm{t}_{1}, \mathrm{t}_{2}, \mathrm{t}_{3}, \mathrm{t}_{4}\right) \geq \mathrm{t}_{1}-\operatorname{Max}\left(\mathrm{t}_{2}, \mathrm{t}_{3}, \mathrm{t}_{4}\right)$

Then $\phi \in \Phi$

\section{MAIN RESULTS}

Theorem 3.1 - Let $(\mathrm{X}, \mathrm{M}, *)$ be a complete $\varepsilon$ - chainable fuzzy metric space and let A, B, S and T be the self mapping of $\mathrm{X}$, satisfying the following condition

(1) $\mathrm{A}(\mathrm{X}) \subseteq \mathrm{T}(\mathrm{X})$ and $\mathrm{B}(\mathrm{X}) \subseteq \mathrm{S}(\mathrm{X})$

(2) The pairs (A, T) and (B, S) are weakly compatible.

(3) $\mathrm{T}(\mathrm{X})$ or $\mathrm{S}(\mathrm{X})$ is complete.

(4) There exists $\mathrm{k} \in(0,1)$ such that

$\phi\left(\left(M(A x, B y, k t), \frac{M(S x, A x, t)+M(A x, T y, t)}{2}\right.\right.$,

$$
M(T y, S x, t), M(T y, B y, k t)) \geq 0
$$

For some $\phi \in \Phi$, every $\mathrm{x}, \mathrm{y} \in \mathrm{X}$ and $\mathrm{t}>0$, then $\mathrm{A}, \mathrm{B}, \mathrm{S}$ and $\mathrm{T}$ have a unique common fixed point in $\mathrm{X}$.

Proof : - Let $\mathrm{x}_{0}$ be any arbitrary point. Since $\mathrm{A}(\mathrm{X}) \subseteq \mathrm{T}(\mathrm{X})$, $\mathrm{B}(\mathrm{X}) \subseteq \mathrm{S}(\mathrm{X})$. So there must exists points $\mathrm{x}_{1}, \mathrm{x}_{2}, \in \mathrm{X}$ such that $A x_{0}=\mathrm{Tx}_{1}$ and $\mathrm{Bx}_{1}=\mathrm{Sx}_{2}$. In general, We get sequence $\left\{\mathrm{y}_{\mathrm{n}}\right\}$ and $\left\{x_{n}\right\}$ in $X$, Such that

$$
\begin{aligned}
& \mathrm{y}_{2 \mathrm{n}}=T x_{2 n+1}=A x_{2 n} \text { and } \\
& y_{2 n+1}=S x_{2 n+2}=B x_{2 n+1} \text { for } \mathrm{n}=0,1,2,
\end{aligned}
$$

Using condition (4) with $\mathrm{x}=\mathrm{x}_{2 \mathrm{n}}, \mathrm{y}=\mathrm{x}_{2 \mathrm{n}+1}$ we get

$$
\begin{gathered}
\phi\left(M\left(A x_{2 n}, B x_{2 n+1}, k t\right), \frac{M\left(S x_{2 n}, A x_{2 n}, t\right)+M\left(A x_{2 n}, T x_{2 n+1}, t\right)}{2},\right. \\
\left.M\left(T x_{2 n+1}, S x_{2 n}, t\right), M\left(T x_{2 n+1}, B x_{2 n+1}, k t\right)\right) \geq 0 \\
\phi\left(M \left(y_{2 n}, y_{2 n+1}, k t, \frac{\left.M\left(y_{2 n-1}, y_{2 n}, t\right)+M\left(y_{2 n}, y_{2 n}, t\right)\right)}{2},\right.\right. \\
\left.M\left(y_{2 n}, y_{2 n-1}, t\right), M\left(y_{2 n}, y_{2 n+1}, k t\right)\right) \geq 0 \\
\phi\left(M \left(y_{2 n}, y_{2 n+1}, k t, \frac{\left.M\left(y_{2 n-1}, y_{2 n}, t\right)+M\left(y_{2 n}, y_{2 n}, t\right)\right)}{2},\right.\right. \\
\left.M\left(y_{2 n}, y_{2 n-1}, t\right), M\left(y_{2 n}, y_{2 n+1}, k t\right)\right) \geq 0 \\
\phi\left(M\left(y_{2 n}, y_{2 n+1}, k t\right), \frac{1+M\left(y_{2 n-1}, y_{2 n}, t\right)}{2},\right. \\
\left.M\left(y_{2 n}, y_{2 n-1}, t\right), M\left(y_{2 n}, y_{2 n+1}, k t\right)\right) \geq 0 \\
\phi \text { is non- increasing in second argument } \\
\phi\left(M\left(y_{2 n}, y_{2 n+1}, k t\right), M\left(y_{2 n-1}, y_{2 n}, t\right),\right.
\end{gathered}
$$




$$
\begin{array}{r}
\left.M\left(y_{2 n}, y_{2 n-1}, t\right), M\left(y_{2 n}, y_{2 n+1}, k t\right)\right) \geq 0 \\
\Rightarrow M\left(y_{2 n}, y_{2 n+1}, k t\right) \geq M\left(y_{2 n-1}, y_{2 n}, t\right)
\end{array}
$$

Similarly we have

$$
M\left(y_{2 n+1}, y_{2 n+2}, k t\right) \geq M\left(y_{2 n+1}, y_{2 n}, t\right)
$$

Therefore for all $\mathrm{n}$ even or odd, we have

$$
M\left(y_{n}, y_{n+1}, k t\right) \geq M\left(y_{n}, y_{n-1}, t\right)
$$

Thus, for any $\mathrm{n}$ and $\mathrm{t}$, we have

$$
M\left(y_{n}, y_{n+1}, k t\right) \geq M\left(y_{n}, y_{n-1}, t\right)
$$

To prove that $\left\{\mathrm{y}_{\mathrm{n}}\right\}$ is a Cauchy sequence, we have

$$
\begin{gathered}
M\left(y_{n+1}, y_{n}, t\right) \geq M\left(y_{n}, y_{n-1}, t / k\right) \geq M\left(y_{n-1}, y_{n-2}, t / k^{2}\right) \geq \\
\ldots \ldots . . \geq M\left(y_{1}, y_{0}, t / k^{n}\right) \rightarrow 1
\end{gathered}
$$

as $n \rightarrow \infty$

Thus the result proved for $m=1$,

By induction hypothesis let result holds for $\mathrm{m}=\mathrm{p}$, so

$$
\begin{gathered}
M\left(y_{n}, y_{n-p+1_{1}}, t\right) \geq M\left(y_{n}, y_{n-p}, t / 2\right) * M\left(y_{n+1}, y_{n-p+1}, t / 2\right) \\
\rightarrow 1 * 1=1
\end{gathered}
$$

Thus the result holds for $\mathrm{m}=\mathrm{P}+1$, hence

$\left\{y_{n}\right\}$ is a cauchy sequence in $X$, which is complete. Therefore $\left\{y_{n}\right\}$ converges to $z$, such that $y_{n} \rightarrow z$ for some $z \in X$. So it follows That $\left\{\mathrm{Ax}_{2 \mathrm{n}}\right\},\left\{\mathrm{Sx}_{2 \mathrm{n}}\right\},\left\{\mathrm{Bx}_{2 \mathrm{n}+1}\right\}$ and $\left\{\mathrm{Tx}_{2 \mathrm{n}+1}\right\}$ also converges to $\mathrm{z}$.

That is, there exists a finite sequence

$\mathrm{X}_{\mathrm{n}}=\mathrm{y}_{1}, \mathrm{y}_{2}, \ldots \ldots \ldots \ldots \mathrm{y}_{\mathrm{n}}=\mathrm{x}_{\mathrm{n}+1}$ such that

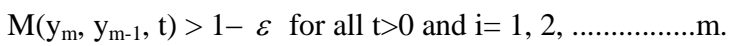

thus we have

$$
\begin{aligned}
\mathrm{M}\left(\mathrm{x}_{\mathrm{n}}, \mathrm{x}_{\mathrm{n}+1}, \mathrm{t}\right) \leq & \mathrm{M}\left(\mathrm{y}_{1}, \mathrm{y}_{2}, \mathrm{t} / 1\right) * \mathrm{M}\left(\mathrm{y}_{2}, \mathrm{y}_{3}, \mathrm{t} / \mathrm{l}\right) * \ldots \ldots \ldots \ldots \\
& \mathrm{M}\left(\mathrm{y}_{\mathrm{m}-1}, \mathrm{y}_{\mathrm{m}}, \mathrm{t} / \mathrm{l}\right) \\
\geq & (1-\varepsilon) *(1-\varepsilon) * \ldots \ldots \ldots \ldots \ldots(1-\varepsilon) \\
\geq & (1-\varepsilon)
\end{aligned}
$$

for $m>n$,

$$
\begin{aligned}
\mathrm{M}\left(\mathrm{x}_{\mathrm{n}}, \mathrm{x}_{\mathrm{m}}, \mathrm{t}\right) & \geq \mathrm{M}\left(\mathrm{x}_{\mathrm{n}}, \mathrm{x}_{\mathrm{n}+1}, \mathrm{t} / \mathrm{m}-\mathrm{n}\right) * \mathrm{M}\left(\mathrm{x}_{\mathrm{n}+1}, \mathrm{x}_{\mathrm{n}+2}, \mathrm{t} / \mathrm{m}-\mathrm{n}\right) * \\
\ldots \ldots . . & * \mathrm{M}\left(\mathrm{x}_{\mathrm{m}-1}, \mathrm{x}_{\mathrm{m}}, \mathrm{t} / \mathrm{m}-\mathrm{n}\right) \\
& \geq(1-\varepsilon) *(1-\varepsilon) * \ldots \ldots \ldots \ldots \ldots \ldots \ldots \ldots \ldots \ldots \\
& \geq(1-\varepsilon)
\end{aligned}
$$

Hence $\left\{x_{n}\right\}$ is a cauchy sequences in $X$, which is complete, therefore $\left\{x_{n}\right\}$ converges to $z \in X$. Hence its subsequence $\left\{\mathrm{Ax}_{2 \mathrm{n}}\right\},\left\{\mathrm{Sx}_{2 \mathrm{n}}\right\},\left\{\mathrm{Bx}_{2 \mathrm{n}+1}\right\}$ and $\left\{\mathrm{Tx}_{2 \mathrm{n}+1}\right\}$ also converges to $\mathrm{z}$.

Case 1:- $\mathrm{T}(\mathrm{X})$ is complete

If we take $\mathrm{z} \in \mathrm{T}(X)$, so there exist $\mathrm{u} \in \mathrm{X}$, such that $\mathrm{z}=\mathrm{Tu}$

Step I Put $\mathrm{x}=\mathrm{x}_{2 \mathrm{n}}$ and $\mathrm{y}=\mathrm{u}$ in the condition (4),

$$
\phi\left(M\left(A x_{2 n}, B u, k t\right), \frac{M\left(S x_{2 n}, A x_{2 n}, t\right)+M\left(A x_{2 n}, T u, t\right)}{2}\right.
$$$$
\left.M\left(T u, S x_{2 n}, t\right), M(T u, B u, k t)\right) \geq 0
$$

as

$\operatorname{Lim} \mathrm{n} \rightarrow \infty$, we get

$$
\begin{gathered}
\phi\left(M(z, B u, k t), \frac{M(z, z, t)+M(z, T u, t)}{2}\right. \\
\phi\left(M(z, B u, k t), \frac{1+M(z, T u, t)}{2}\right. \\
M(T u, z, t), M(T u, B u, k t)) \geq 0
\end{gathered}
$$

Since $\mathrm{Tu}=\mathrm{z}$

$$
\phi\left(M(z, B u, k t), \frac{1+M(z, z, t)}{2}, M(z, z, t), M(z, B u, k t)\right) \geq 0
$$$$
\varphi(M(z, B u, k), 1,1, M(z, B u, k t)) \geq 0
$$

$\phi$ is non increasing in second and third arguments

$\varphi(M(z, B u, k), M(z, B u, t), M(z, B u, t), M(z, B u, k t)) \geq 0$

$M(z, B u, K) \geq M(z, B u, t)$,

So $\mathrm{z}=\mathrm{Bu}\{$ by lemma $\}$

Hence $\mathrm{z}=\mathrm{Bu}=\mathrm{Su}=\mathrm{Tu}$

Now $(\mathrm{B}, \mathrm{S})$ is weakly compatible, so $\mathrm{BSu}=\mathrm{SBu}$,

there by $\mathrm{Bz}=\mathrm{Sz}$

Step II Put $\mathrm{x}=\mathrm{x}_{2 \mathrm{n}}$ and $\mathrm{y}=\mathrm{z}$ in condition (4) we get

$$
\begin{gathered}
\phi\left(M\left(A x_{2 n}, B z, k t\right), \frac{M\left(S x_{2 n}, A x_{2 n}, t\right)+M\left(A x_{2 n}, T z, t\right)}{2}\right. \\
\left.M\left(T z, S x_{2 n}, t\right), M(T z, B z, k t)\right) \geq 0
\end{gathered}
$$

Taking Lim $\mathrm{n} \rightarrow \infty$, we get

$$
\begin{aligned}
& \phi\left(M(z, B z, k t), \frac{M(z, z, t)+M(z, T z, t)}{2},\right. \\
& \phi(M(T z, z, t), M(T z, B z, k t)) \geq 0 \\
& \text { Since z }=\mathrm{Tz}, \mathrm{z} \in \mathrm{T}(\mathrm{X}), \text { so we have } \\
& \phi\left(M(z, B z, k t), \frac{M(z, z, t)+1}{2}, M(z, z, t), M(z, B z, k t)\right) \geq 0 \\
& \varphi(M(z, B z, k), 1,1, M(z, B z, k t)) \geq 0
\end{aligned}
$$

Since $\phi$ is non- increasing in Second \& Third argument.

$$
\varphi(M(z, B z, k), M(z, B z, t), M(z, B z, t) M(z, B z, k t)) \geq 0
$$

So $M(z, B z, l t) \geq(z, B z, t)$

Hence $\mathrm{z}=\mathrm{Bz}=\mathrm{Tz}(\Theta \mathrm{z}=\mathrm{Tz})$

Step III As $B(X) \subseteq S(X)$ Let there exists $v \in X$,

such that $\mathrm{z}=\mathrm{Bz}=\mathrm{Sv}$

Put $\mathrm{x}=\mathrm{v}, \mathrm{y}=\mathrm{z}$ in condition (4) 
$\phi\left(M(A v, B z, k t), \frac{M(S v, A v, t)+M(A v, T z, t)}{2}, M(T z, S v, t), M(T z, B z, k t)\right) \geq 0$

$\phi\left(M(A v, z, k t), \frac{M(z, A v, t)+M(A v, z, t)}{2}, M(z, z, t), M(z, z, k t)\right) \geq 0$

$\phi(M(A v, z, k), M(z, A v, t), 1,1)) \geq 0$

$\phi$ is non increasing in third and fourth arguments.

$\varphi(M(A v, z, l t), M(z, A v, t), M(z, A v, t), M(z, A v, t)) \geq 0$

$M(A v, z, K t) \geq M(A v, z, t)$

$\mathrm{Av}=\mathrm{z} \quad$ \{by lemma 2.3$\}$

Now since $\mathrm{A} \subseteq \mathrm{T}$ so $\mathrm{z}=\mathrm{Av} \in \mathrm{T}$ Therefore $\mathrm{z}=\mathrm{Av}=\mathrm{Tv}$

Now as (A.T) is weakly compatible so

$\mathrm{ATv}=\mathrm{TAv}$ such that $\mathrm{Az}=\mathrm{Tz}$

So combining all the results, we have

$\mathrm{Az}=\mathrm{Tz}=\mathrm{Bz}=\mathrm{Sz}=\mathrm{z}$

Case II :- $S(X)$ is complete if we take $z \in S(x)$, so there exists. $\mathrm{p} \in \mathrm{X}$, such that $\mathrm{z}=\mathrm{Tp}$, The proof is same as in case I. So similarly we can show that

$\mathrm{Az}=\mathrm{z}, \mathrm{Bz}=\mathrm{z}, \mathrm{Tz}=\mathrm{z}$ and $\mathrm{Sz}=\mathrm{z}$

Hence $\mathrm{z}=\mathrm{Az}=\mathrm{Tz}=\mathrm{Bz}=\mathrm{Sz}$

Thus $z$ is the common fixed point of A.B.S. and T.

\section{Uniqueness:-}

Let $\mathrm{p}$ and $\mathrm{z}$ be the two common fixed points of maps A, B, S, and T. Put $x=z$ and $y=p$ in condition (4) we get

$$
\begin{aligned}
& \phi\left(M(A z, B p, k t), \frac{M(S z, A z, t)+M(A z, T p, t)}{2}, M(T p, S z, t), M(T p, B p, K t) \geq 0\right) \\
& \phi\left(M(z, p, k t), \frac{M(z, z, t)+M(z, p, t)}{2}, M(p, z, t), M(p, p, t)\right) \geq 0 \\
& \phi\left(M(z, p, k t), \frac{1+M(z, p, t)}{2}, M(p, z, t), 1\right) \geq 0 \\
& \phi(M(z, p, k t), M(z, p, t), M(z, p t), M(z, p, t)) \geq 0
\end{aligned}
$$

So $\mathrm{M}(\mathrm{z}, \mathrm{p}, \mathrm{kt}) \geq \mathrm{M}(\mathrm{z}, \mathrm{p}, \mathrm{t})$

Hence $\mathrm{z}=\mathrm{t}$

So $\mathrm{z}$ is the unique common fixed points of $\mathrm{A}, \mathrm{B}, \mathrm{S}$, and $\mathrm{T}$.

Remark 3.1: If $\mathrm{S}=\mathrm{T}$ and $\mathrm{A}=\mathrm{B}$ then condition from (1), (2), (3) it is clear that the pair (A, T) is weakly compatible and $\mathrm{AX} \subseteq \mathrm{TX}$. In such case sequence occurs as $\left\{\mathrm{Ax}_{2 \mathrm{n}}\right\}=\left\{\mathrm{Tx}_{\mathrm{n}+1}\right\}$.

Remark 3.2: If $\mathrm{S}=\mathrm{T}$ and $\mathrm{A}=\mathrm{B}$ then condition from (1), (2), (3) it is clear that the pair (A, T) and (B, S) are weakly compatible and so $\mathrm{A}(\mathrm{X}) \cup \mathrm{B}(\mathrm{X}) \subseteq \mathrm{T}(\mathrm{X})$. In such case sequence occurs as follows

$\mathrm{Ax}_{2 \mathrm{n}}=\mathrm{Tx}_{2 \mathrm{n}+1}$ and $\mathrm{Bx}_{2 \mathrm{n}+1}=\mathrm{Sx}_{2 \mathrm{n}+2}$

\section{CONCLUSION}

We establish A Common Fixed Point Theorem in Fuzzy Metric Spaces satisfying implicit relations. There are some possible application in real engineering, economics in dealing with problems arising in approximation theory, information system in future scope we can obtain new implicit relation to relax conditions.

\section{ACKNOWLEDGMENTS}

Our thanks to the Mr. Bharat Singh faculty of SOS and E.IPS Academy, Indore M.P. (India) who have contributed towards making of the paper and the authors would like to thanks the referees for their helpful and valuable comments.

\section{REFERENCES}

[1] Bharduwaj R. K. et al Some results on fuzzy metric spaces, proceeding world Congress on Engineering 2001 Vol I, WCE 2011, London, U.K.

[2] Cho Y. J. Fixed point in fuzzy metric space, Journal of fuzzy mathematics 4(1997), 949 - 962.

[3] George A. and Veeramani P., On some results in fuzzy metric spaces, fuzzy sets and systems 64 (1994), 395 399.

[4] George A. \& Veeramani P., On some results in fuzzy metric spaces, fuzzy sets and systems, 64 (1994), 395 399.

[5] Grabicc M., Fixed points in fuzzy metric spaces, fuzzy sets and systems 27 (1988), $385-389$.

[6] Imdad M., Kumar S. \& Khan M. S., Remarks some fixed point theorem Radovi mathematics II (2002), 135 - 143.

[7] Jungck G. and Rhoodes B. E., Fixed points for set valued functions without continuity, Indian J. Pure and appli., Math . 29 (1998), no., 3, 227 - 238.

[8] Kramosil I. and Michalek J., Fuzzy metric and statistical metric spaces, Kybernetric 11 (1975) 326 - 337.

[9] Manro S. et al ,Common fixed point theorems in fuzzy metric spaces3,(2012),151-158

[10] Mishra S. N., Sharma N. S. and Singh S. L., Common fixed point of maps on fuzzy metric spaces, Int. J. Math. Math, Sci. II (1994).

[11] Popa V., Some fixed point theorems for weakly compatible mapping, Radovi Mathematics 10 (2001), 245- - 252

[12] Rodrigues L .J. and Ramaguero S. The Hausdorff Fuzzy Metric on compact sets ,Fuzzy sets and systems14(2004),273-283

[13] Rana R. et al, Fixed point theorem in fuzzy metric spaces using implicit relations, Int. J. computer Application, (2010), (0975 - 8887)

[14] Singh B. \& Jain S., Semi compatibility \& fixed point theorems in fuzzy metric spaces using implicit relation, Int. J. math \& math sci., 16 (2005), 2617 - 2629.

[15] Singh B. and Chauhan M. S., Common fixed points compatible maps in fuzzy metric space, fuzzy sets and system, 15 (2000), $471-475$.

[16] Shrivastava R. et al ,Fixed point theorem and fuzzy metric spaces, Technical journal Vol2, Issue1, June 2011

[17] Zadeh L. A., fuzzy sets, Inform and control 89 (1965), 338-353 